\title{
Genome-wide discovered psychosis-risk gene ZNF804A impacts on white matter microstructure in health, schizophrenia and bipolar disorder
}

Emma-Jane Mallas, Francesco Carletti, Christopher A Chaddock, James Woolley, Marco M Picchioni, Sukhwinder S Shergill, Fergus Kane, Matthew PG Allin, João R Sato, Gareth J Barker, Diana P Prata

Background. Schizophrenia (SZ) and bipolar disorder (BD) have both been associated with reduced microstructural white matter integrity using, as a proxy, fractional anisotropy (FA) detected using diffusion tensor imaging (DTI). Genetic susceptibility for both illnesses has also been positively correlated in recent genome-wide association studies with allele $A$ (adenine) of single nucleotide polymorphism (SNP) rs1344706 of the ZN4804A gene.

However, little is known about how the genomic linkage disequilibrium region tagged by this SNP impacts on the brain to increase risk for psychosis. This study aimed to assess the impact of this risk variant on FA in patients with SZ, in those with BD and in healthy controls. Methods. 230 individuals were genotyped for the rs1344706 SNP and underwent DTI. We used tract-based spatial statistics (TBSS) followed by an analysis of variance, with threshold-free cluster enhancement (TFCE), to assess underlying effects of genotype, diagnosis and their interaction, on FA. Results. As predicted, statistically significant reductions in FA across a widely distributed brain network ( $p<0.05$, TFCE-corrected) were positively associated both with a diagnosis of $\mathrm{SZ}$ or $\mathrm{BD}$ and with the double (homozygous) presence of the ZNF804A rs1344706 risk variant (A). The main effect of genotype was medium ( $d=0.48$ in a 44054-voxel cluster) and the effect in the SZ group alone was large ( $d=1.01$ in a 51260-voxel cluster), with no significant effects in BD or controls, in isolation. No areas under a significant diagnosis by genotype interaction were found. Discussion. We provide the first evidence in a predominantly Caucasian clinical sample, of an association between ZN4804A rs1344706 A-homozygosity and reduced FA, both irrespective of diagnosis and particularly in SZ (in overlapping brain areas). This suggests that the previously observed involvement of this genomic region in psychosis susceptibility, and in impaired functional connectivity, may be conferred through it inducing abnormalities in white matter microstructure. 
1 Genome-wide discovered psychosis-risk gene ZNF804A impacts on white matter

2 microstructure in health, schizophrenia and bipolar disorder

4 Running title: ZNF804A impacts on white matter

6 Emma-Jane Mallas ${ }^{1,2}$, MSc, Francesco Carletti ${ }^{3}, \mathrm{PhD}$, Christopher A Chaddock ${ }^{1}$, PhD, James

7 Woolley $^{4}$, MRCP, Marco M Picchioni ${ }^{1,} 5$, PhD, Sukhi Shergill ${ }^{1}, \mathrm{PhD}$, Fergus Kane ${ }^{6}$, PhD,

8 Matthew Allin ${ }^{1}, \mathrm{MD}$, João Ricardo $\mathrm{Sato}^{7}, \mathrm{PhD}$, Gareth J Barker ${ }^{8}, \mathrm{PhD}$, Diana P $\underline{\text { Prata }}^{8,}$ 9§, PhD.

$10{ }^{1}$ Department of Psychosis Studies, Institute of Psychiatry, Psychology and Neuroscience, King's 11 College London, London, UK

$12{ }^{2}$ Computational, Cognitive and Clinical Neuroimaging Laboratory, Division of Brain Sciences,

13 Faculty of Medicine, Imperial College London, London, UK

$14{ }^{3}$ Department of Neuroradiology, John Radcliffe Hospital, Oxford University Hospitals NHS

15 Trust, Oxford, UK

$16{ }^{4}$ Psychological Medicine, Royal Brompton \& Harefield NHS Trust, London, UK

17 5. Andrews Academic Department, Northampton, UK

$18{ }^{6}$ Department of Psychology, Institute of Psychiatry, Psychology and Neuroscience King's

19 College London, London, UK

$20{ }^{7}$ Center of Mathematics, Computation and Cognition, Universidade Federal do ABC, Santo 21 Andre, Brazil

$22{ }^{8}$ Department of Neuroimaging, Institute of Psychiatry, Psychology and Neuroscience, King's 23 College London, London, $U K$ 
27 \$Corresponding author: Diana Prata, diana.prata@kcl.ac.uk

\section{Abstract}

Background. Schizophrenia (SZ) and bipolar disorder (BD) have both been associated with reduced microstructural white matter integrity using, as a proxy, fractional anisotropy (FA) detected using diffusion tensor imaging (DTI). Genetic susceptibility for both illnesses has also been positively correlated in recent genome-wide association studies with allele A (adenine) of 34 single nucleotide polymorphism (SNP) rs1344706 of the ZN4804A gene. However, little is known about how the genomic linkage disequilibrium region tagged by this SNP impacts on the brain to increase risk for psychosis. This study aimed to assess the impact of this risk variant on FA in patients with SZ, in those with BD and in healthy controls.

Methods. 230 individuals were genotyped for the rs1344706 SNP and underwent DTI. We used tract-based spatial statistics (TBSS) followed by an analysis of variance, with threshold-free

41 cluster enhancement (TFCE), to assess underlying effects of genotype, diagnosis and their interaction, on FA.

Results. As predicted, statistically significant reductions in FA across a widely distributed brain network ( $\mathrm{p}<0.05$, TFCE-corrected) were positively associated both with a diagnosis of $\mathrm{SZ}$ or BD and with the double (homozygous) presence of the ZNF804A rs1344706 risk variant (A). The 
47 main effect of genotype was medium ( $\mathrm{d}=0.48$ in a 44054-voxel cluster) and the effect in the SZ

48 group alone was large ( $\mathrm{d}=1.01$ in a 51260 -voxel cluster), with no significant effects in BD or 49 controls, in isolation. No areas under a significant diagnosis by genotype interaction were found.

51 Discussion. We provide the first evidence in a predominantly Caucasian clinical sample, of an association between ZN4804A rs1344706 A-homozygosity and reduced FA, both irrespective of

53 diagnosis and particularly in SZ (in overlapping brain areas). This suggests that the previously 54 observed involvement of this genomic region in psychosis susceptibility, and in impaired 55 functional connectivity, may be conferred through it inducing abnormalities in white matter 56 microstructure. 


\section{Introduction}

59 Schizophrenia (SZ) and bipolar disorder (BD) are major psychiatric illnesses that have a

60 profound effect on an individual's mood, cognition and behavior. Lifetime prevalence of SZ and

$61 \mathrm{BD}$ is about $4 \%{ }^{1}$ and $0.5 \%^{2}$ respectively. Both illnesses are highly heritable: up to $80 \%$ (SZ)

62 and 93\% (BD), but their common and specific etiological and pathophysiological causes are

63 poorly understood ${ }^{3}$.

64

65 One of the first genetic variants to achieve genome-wide significance for an association with 66 both disorders, as well as independent replications, was the single nucleotide polymorphism 67 (SNP) rs1344706 tagging an intronic region of the zinc-finger protein (ZNF) 804A gene ${ }^{3}$. The human ZNF804A gene, located on chromosome 2q32.1, codes for a protein consisting of 1210 amino acids. The protein contains one $\mathrm{C}_{2} \mathrm{H}_{2}$ type zinc-finger domain ${ }^{4}$, which being typical of DNA/RNA-binding motifs, indicates that it may act as a transcription factor. Expressed in the brain ${ }^{5}$, ZNF804A does seem to be involved in gene regulation ${ }^{6}$, including that of genes that are

72 known to be SZ-candidate risk genes: COMT, DRD2, PRSS16 and PDE4 ${ }^{7}$. It has been implicated in neurodevelopmental processes ${ }^{8}$, cell adhesion, neurite outgrowth, dendritic branching and synapse formation ${ }^{9}$, differentiation of oligodendrocytes and proliferation of 75 oligodendrocyte progenitors ${ }^{10}$.

77 The rs1344706 psychosis risk allele (i.e. A) of ZNF804A has lower binding affinity for proteins 78 in the cell nucleus, such as transcription factors ${ }^{11}$ and, potentially as a result of this, shows 79 significantly increased expression compared to its counterpart ( $\mathrm{C}$ allele) in healthy controls ${ }^{10}$. 80 Furthermore, this SNP appears to selectively modulate a novel mRNA isoform, ZNF804A ${ }^{E 3 E 4}$ in 
81 the human fetal brain (risk allele homozygotes demonstrating lower expression than

82 heterozygotes or non-risk homozygotes), with no effect on the full-length ZNF804A mRNA ${ }^{12}$.

83 The authors propose these findings suggest the $\mathrm{ZNF} 804 \mathrm{~A}^{\mathrm{E} 3 \mathrm{E} 4}$ isoform may mediate the

84 association of rs1344706 with psychosis. Nevertheless, the role ZNF804A, or rs1344706, in

85 psychiatric illness remains relatively unknown, with in vivo research of its involvement in brain

86 structure and function highly warranted.

87

88 Neuroimaging studies of ZNF804A rs1344706 have not found an effect of the risk allele on

89 regional brain activation, but rather on functional connectivity disruption between prefrontal

90 regions $4,13-15$, which suggests its impact is on white matter (WM). Functional connectivity

91 abnormalities are a common finding in $\mathrm{BD}$ and more so in SZ ${ }^{16-18}$. WM abnormalities are also

92 found in $\mathrm{SZ}^{19}$ and $\mathrm{BD}^{20}$, including regional deficits common to both ${ }^{21-23}$. However, the impact

93 of rs1344706 on WM volume, density and integrity is still unclear, as we reviewed elsewhere ${ }^{3}$.

94 Fractional anisotropy (FA), measured using diffusion tensor imaging (DTI) is a putative proxy of

95 WM microstructural integrity ${ }^{24}$. It is robustly found to be lower in SZ, and to a lesser extent, in

$96 \mathrm{BD}$, in a diverse range of brain regions ${ }^{25,26}$. Reduced FA can be detected in very early stages of

97 illness 27 , suggesting microstructural WM abnormalities are involved in the underlying

98 neuropathophysiology of these diseases. FA, and other measures of WM microstructure (such as

99 geodesic anisotropy and diffusivity), is reported to be highly heritable ${ }^{28}$. Several studies also

100 report FA abnormalities in first-degree relatives of patients with $\mathrm{SZ}$ and $\mathrm{BD}{ }^{29-31}$ with FA

101 decreasing with increasing genetic liability to psychosis ${ }^{32,33}$. This evidence provides support FA

102 being a potentially useful endophenotype for exploration of the mechanism of action through

103 which ZNF804A rs1344706 is exerting increased disease risk. 
105 The effect of rs1344706 on FA is still unclear, with three negative ${ }^{34-36}$ and the following two

106 positive association reports 37,38 . Within the Chinese SZ population, risk allele homozygotes

107 were found to have reduced FA in bilateral parietal lobes and left cingulate gyrus compared to

108 non-risk allele carriers ${ }^{37}$. Furthermore, within risk allele homozygotes, SZ patients showed

109 decreased FA in the aforementioned areas, as well as the right medial temporal lobe ${ }^{37}$.

110 Consistently, in the healthy Caucasian population, reduced FA was associated with the risk allele

111 A in a dose-dependent manner, in right parietal WM, left forceps minor and the anterior

112 body/genu of the corpus callosum ${ }^{38}$.

113

114 Taken together, the associations of reduced FA with SZ, BD, and the rs 1344706 risk allele A,

115 suggest that WM microstructural abnormalities may be part of the pathophysiological

116 mechanism through which ZNF804A rs1344706 (or other polymorphism(s) in high linkage

117 disequilibrium with it) increases risk for SZ ad BD. However, given that assessments of the

118 impact of rs1344706 ZNF804A on WM microstructure have thus far yielded mixed results and

119 are hard to compare given that they were found in different ethnicities or diagnosis statuses ${ }^{3}$, the

120 present further study of the effect of rs 1344706 on FA in a predominantly Caucasian and healthy

121 as well as clinical sample, is highly warranted.

122

123 In the present study, we aimed to test two main hypotheses: 1) We aimed to assess the effect of

124 ZNF804A rs1344706 genotype on FA in a predominantly Caucasian sample. We hypothesized

125 that risk allele homozygotes (AA) would show reduced FA compared to C (cytokine) carriers,

126 across diagnoses, at least in some WM regions; 2) We aimed to explore whether this genotype 
127 impacted FA differentially between the different diagnostic groups. Given that both allele A and

128 reduced FA are correlated to SZ and, somewhat less strongly, to $\mathrm{BD} 10,26,30,39,40$, we

129 hypothesized that the genotype effect would be stronger in SZ and BD, compared to controls,

130 and perhaps more so in SZ compared to BD. A whole brain approach, without a priori region-

131 specific hypotheses, was taken given previous reports implicating a wide range of spatially

132 extensive brain regions. In addition, we report the impact of SZ or BD on FA for completeness. 


\section{Methods}

\section{Participants}

136 Our sample $(n=230)$ consisted of patients with SZ $(n=63)$, BD (type 1 or type 2; 77\% of which

137 with psychosis; $n=43)$ and controls $(n=124)$, which had participated in seven previous research

138 studies ${ }^{41-47}$ at the Institute of Psychiatry, Psychology and Neuroscience (IoPPN), King's College

139 London. Individuals were collated from those sub-samples, with any relatives excluded. In the

140 case of concordant monozygotic twins, one twin from each pair was removed at random; for

141 discordant or dizygotic twins pairs, priority of inclusion was given to the individual with the

142 genotype or, in this order of preference, the diagnosis, that was less frequent - in order to balance

143 genotype and diagnostic group sizes as much as possible. Each participant was assigned to two

144 groups: a diagnosis group (SZ, BD or control) and, after genotyping (see below), a genotype

145 group (ZNF+ which included risk allele (A) homozygotes, or ZNF- which included

146 heterozygotes and non-risk allele (C) homozygotes). Again, the merge within ZNF- had the

147 purpose of maximizing counterbalance for this SNP (as is commonly practiced in the literature

148 e.g. ${ }^{48-51}$ ), given the very low frequency of allele $\mathrm{C}$ in the Caucasian population.

150 The study was approved by the National Health Service South East London Research Ethics

151 Committee, UK (Project "Genetics and Psychosis (GAP)" reference number 047/04). All 152 subjects provided written informed consent at the time of participation. Patients were recruited

153 from the South London and Maudsley National Health Service Trust (SLaM). Diagnosis,

154 according to the criteria of the Diagnostic and Statistical Manual of Mental Disorders (DSM) $4^{\text {th }}$

155 edition 52 was ascertained by an experienced psychiatrist using a structured diagnostic interview

156 (with instruments detailed elsewhere ${ }^{53}$ ). All SZ and BD patients were in a stable clinical state 
157 and all SZ and some BD were treated with antipsychotic medication (from which

158 Chlorpromazine-equivalence was calculated, see Table 1). Exclusion criteria applied to all

159 participants were a history of significant head injury and current (last 12 months) substance

160 dependency according to DSM-IV diagnostic criteria. Controls were excluded if they had any

161 personal or family history of a psychotic spectrum disorder. In order to follow the gold standard

162 of experimental design that a control group must be matched to the experimental group on all

163 variables except the one isolated for study, and avoid a biased 'super-normal' control group ${ }^{54}$,

164 healthy participants with a previous diagnosis of any other Axis I disorder (or family history)

165 were not excluded given these are frequently present in SZ and BD. Nevertheless, none were

166 psychiatrically unwell or on any psychiatric medication at the time of participation.

167

168 Genotyping

169 DNA was extracted from blood samples or buccal swabs following a standard protocol ${ }^{55}$. The

170 TaqMan SNP Genotyping Assay ${ }^{56}$ was performed for SNP rs1344706 (A/C) blind to any

171 phenotype, at the Social Genetic and Developmental Psychiatry Centre (SGDP) lab, King's

172 College London. Possible genotype outcomes were thus C homozygous (CC, cytokine -

173 cytokine), heterozygous (AC, adenine-cytokine) or A homozygous (AA, adenine - adenine).

174 Distribution of Caucasian genotype frequencies $(0.13 \mathrm{CC}, 0.41 \mathrm{CA}, 0.46 \mathrm{AA})$ was consistent

175 with Hardy-Weinberg Equilibrium, calculated using Michael H. Court's online calculator 57 in

176 Caucasian patients and controls (patients $\chi^{2}=0.62, \mathrm{df}=1, \mathrm{p}=0.43$; controls $\chi^{2}=0.29, \mathrm{df}=1, \mathrm{p}=0.59$ )

177 and African-American and Black Caribbean (patients $\chi^{2}=0.29, \mathrm{df}=1, \mathrm{p}=0.77$; controls $\chi^{2}=0.03$,

$178 \mathrm{df}=1, \mathrm{p}=0.87)$. Genotype counts are in Table 1. 


\section{Image Acquisition}

181 Magnetic Resonance Imaging (MRI) data were acquired using a 1.5T GE Signal LX system

182 (General Electric, Milwaukee, WI, USA) in the Mapother House MR unit at the Maudsley

183 Hospital, SLaM, London, UK, with actively shielded magnetic field gradients (maximum

184 amplitude $40 \mathrm{mT} / \mathrm{ml}$ ). A standard quadrature birdcage head coil was used for both

185 radiofrequency $(\mathrm{RF})$ transmission and signal reception. DTI data was acquired using a multi-

186 slice peripherally-gated echo planar imaging (EPI) sequence, optimized for precise measurement

187 of the diffusion tensor in parenchyma, from 60 contiguous near-axial slice locations for whole

188 brain coverage, with isotropic $(2.5 \times 2.5 \times 2.5 \mathrm{~mm})$ resolution. At each slice location, 7 images

189 were acquired with no diffusion gradients applied $(b=0)$, together with 64 diffusion-weighted

190 images in which gradient directions were uniformly distributed in space. Acquisition parameters

191 were: echo time $(\mathrm{TE})=107 \mathrm{~ms}$, effective repetition time $=15 \mathrm{R}-\mathrm{R}$ intervals, duration of the

192 diffusion encoding gradients $=17.3 \mathrm{~ms}$, with a maximum diffusion weighting $=1300 \mathrm{~s} / \mathrm{mm}^{2}$.

193 Further details are given elsewhere ${ }^{58}$.

195 DTI Data Processing

196 The raw DTI data were corrected for head movement and eddy current induced distortions, and

197 brain-extracted using the Brain Extraction Tool (BET) ${ }^{59}$ to exclude non-brain voxels. After

198 visual inspection, the BET threshold was adjusted to 0.2 to ensure a balance between complete

199 scalp removal and inappropriate erosion of brain tissue, not achieved with the default parameter

200 of 0.5 . FA images were created (with a mask defined by a binarised version of this brain-

201 extracted image) by fitting a tensor model to the raw diffusion data using the Functional MRI of 
202 the Brain lab (FMRIB)'s Diffusion Toolbox (FDT) within FMRIB software library (FSL) as

203 described elsewhere ${ }^{60}$.

204

205 Voxel-wise statistical analysis of the FA data was carried out using tract-based spatial statistics 206 (TBSS) ${ }^{61}$, part of FSL ${ }^{62}$. All subjects' FA data were aligned to FMRIB58_FA 1x1x1mm 207 standard space (an average of the FA images of 58 healthy adults) using the nonlinear 208 registration tool FNIRT ${ }^{63,64}$, which uses a b-spline representation of the registration warp field 209 65. The entire aligned dataset was then affine-transformed into a 1x1x1mm MNI152 space, 210 resulting in a standard space version of each subject's FA image, from which the mean FA image

211 was created and thinned, creating a mean FA skeleton. Each subject's aligned FA data were 212 projected onto this skeleton and the resulting data fed into voxel-wise cross-subject statistics.

\section{Statistical Analyses}

215 Demographic differences between diagnostic or genotype groups were analyzed in Statistical

216 Package for Social Sciences (SPSS) ${ }^{66}$ using independent t-tests, chi-square and analysis of 217 variance (ANOVA). Scores of full scale IQ from the Wechsler Abbreviated Scale of Intelligence 218 (WASI) ${ }^{67}$, the Wechsler Adult Intelligence Scale - Revised (WAIS-R) ${ }^{68}$ or the National Adult

219 Reading Test (NART) ${ }^{69}$, were standardised to z-scores to permit between-group demographic 220 comparison. The type of test used was balanced between diagnostic or genotype groups (Table 221 1).

222

223 The FSL Randomise tool ${ }^{70}$ was used to perform permutation-based non-parametric inference on 224 the skeletonized FA data at a threshold of 0.2 (TBSS default) with 10,000 permutations. The 
225 significance level was set at $\mathrm{p}<0.05$ after multiple comparisons correction using threshold-free

226 cluster enhancement (TFCE) ${ }^{71}$, an approach that allows the significance of a target voxel to take

227 into account not only the amplitude of the signal (in this case FA) but also the contribution of

228 both the spatial extent and the magnitude of supporting voxels. To assess the main effect of 229 genotype, of diagnostic group and their interaction on FA, an ANOVA-style design matrix was

230 built with genotype (ZNF+ vs. ZNF-) and diagnosis (SZ, BD and controls) as the two 231 independent variables. Mean FA in the largest cluster of each effect was graphically plotted for a 232 visual overview. Cohen's d measure of effect was calculated using mean FA of the largest 233 cluster, to provide an approximate representation of the magnitude of effect found via TFCE 234 analysis.

235

236 WM labelling, in accordance with JHU ICBM-DTI-81 WM Atlas ${ }^{72}$, provided in FSL, was used 237 to determine the anatomical location of significant FA clusters; only those with $>1 \%$ probability 238 were included in the cluster table. Where results were retrieved as 'Unclassified', labelling was 239 carried out manually using the MRI Atlas of Human WM ${ }^{73}$. Results were overlaid on MNI152 $240(1 \mathrm{~mm})$ standard template and displayed in radiological convention. 


\section{Results}

\section{Demographics}

244 Table 1 displays the participants' demographics. BD patients (mean age $=41.1, \mathrm{SD}=12.3$ ) were

245 significantly $(\mathrm{p}<0.05)$ older than $\mathrm{SZ}$ patients (mean age $=33.8, \mathrm{SD}=10.7 ; \mathrm{t}(104)=-3.2, \mathrm{p}<0.001$

246 and controls (mean age $=35.8, \mathrm{SD}=13.4 ; \mathrm{t}(165)=-2.3, \mathrm{p}=0.02$ ). There was no significant

247 difference in age between controls and $\mathrm{SZ}(\mathrm{t}(185)=-1.11, \mathrm{p}=0.27)$. SZ patients (mean CPZ score

$248=696.9, \mathrm{SD}=613.0)$ had a significantly higher $(\mathrm{t}(104)=3.3, \mathrm{p}<0.001) \mathrm{CPZ}$-equivalent score than

249 BD (mean CPZ score $=341.6, \mathrm{SD}=434.6$ ). There were significantly $\left(\chi^{2}=17.2, \mathrm{p}<0.001\right)$ more

250 males (50M:13F) in SZ than BD (18M:25F) or control (67M:57F) groups. There were no

251 significant differences between diagnostic groups in IQ, years of education, ethnicity or

252 handedness. Between ZNF+ and ZNF- groups, there were no significant differences in age, IQ,

253 CPZ equivalents, years of education, sex or handedness. There was a lower proportion of Black

254 African-American and Black Caribbean ethnicities in the ZNF- $(n=3)$ group compared to ZNF+ 255 ( $n=21)$ group $\left(\chi^{2}=20.9, d f=6, p<0.001\right)$, which was due to the A allele being naturally more 256 common in these ethnicities than in the Caucasian population ${ }^{74}$.

\section{Main Effect of Genotype on FA}

Irrespective of diagnosis, the ZNF+ showed significantly reduced FA compared to the ZNFgroup in the genu and body of the corpus callosum, bilaterally in the anterior corona radiata, external capsule, superior longitudinal fasciculus, posterior thalamic radiation, middle cerebellar

262 peduncle and in the right inferior and superior cerebellar peduncle and left anterior limb of 263 internal capsule, with the largest TFCE-corrected significant cluster encompassing 44054 voxels 264 (Figure 1 and Table 2). A post hoc analysis in SPSS showed that neither sex $(\mathrm{F}=1.15, \mathrm{df}=1$, 
$265 \mathrm{p}=0.29)$ nor ethnicity $(\mathrm{F}=0.58, \mathrm{df}=1, \mathrm{p}=0.45)$ explained FA variance in the largest cluster. Age 266 was a significant contributor $(\mathrm{F}=19.32, \mathrm{df}=1, \mathrm{p}<0.001)$ but when it was included in the model, 267 genotype remained a significant explanatory variable $(\mathrm{F}=12.27, \mathrm{df}=1, \mathrm{p}<0.001)$. There were no 268 regions where FA was significantly lower in the ZNF- group compared to ZNF+ group.

270 For a better characterization of this main effect, a post-hoc inspection comparing the mean FA 271 within the largest cluster, between genotype groups, in each diagnostic group, further revealed 272 that this main effect was mainly driven by the genotype effect in SZ and in BD (Figure 1b).

273

a

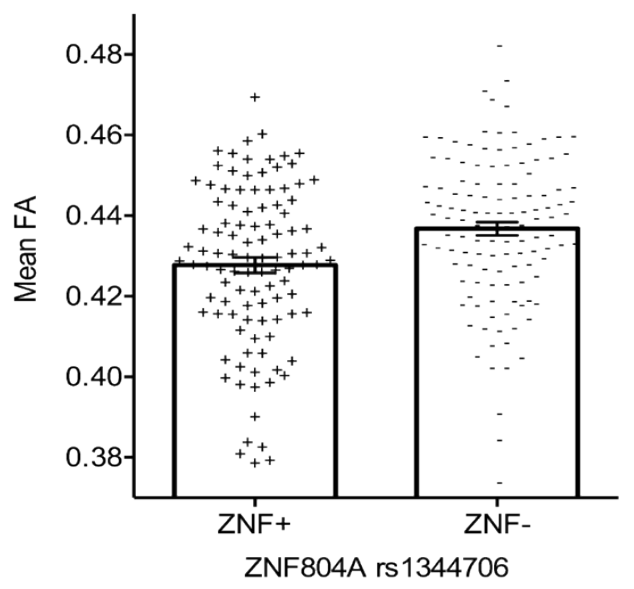

b

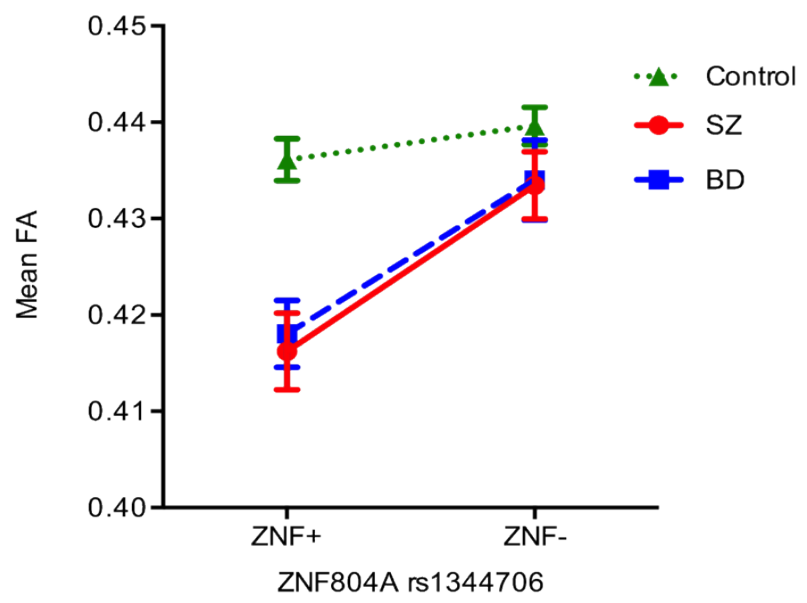

Figure 1 a. FA was significantly higher in the high-risk (A homozygotes; $\mathrm{ZNF}+$ ) group compared to the lowrisk (C-carriers; ZNF-) group ( $<<0.05$, TFCE-corrected), irrespective of diagnosis in brain areas mapped in Figure 2. Post-hoc analysis revealed that mean FA of ZNF+ was lower by half of a standard deviation 
280

281

282

283

284

285

286

287

288

289

290

291

292

293

294

295

296

297

298

299

300

main effect of genotype cluster (44054 voxels), the effect in SZ (Cohen's $d=0.83)$ and BD $($ Cohen's $d=0.89)$ was, all voxels averaged, 'large' while the effect in controls was 'small' (Cohen's $\mathrm{d}=0.2)-$ from a post-hoc analysis. As in subsequent figures, 'Mean FA' refers to the mean FA of the largest TFCE -corrected significant cluster, rather than to mean FA across the whole brain; with individual data points in "a." representing the mean FA of each individual within the same cluster.

\section{Effect of Genotype on FA in SZ}

When we tested, across the brain, for an effect of genotype in each diagnostic group separately, we found no significant effect of genotype in controls or in $\mathrm{BD}(\mathrm{p}<0.05$, TFCE-corrected $)$. There was however a significant effect of genotype within the SZ group on its own in the genu, body and splenium of the corpus callosum, bilaterally in the anterior corona radiata, superior longitudinal fasciculus and uncinate fasciculus, right superior corona radiata, posterior thalamic radiation (including optic radiation), external capsule, superior cerebellar peduncle, inferior cerebellar peduncle, cingulum (cingulate gyrus) and the left corticospinal tract and medial lemniscus, with the largest TFCE-corrected significant cluster encompassing 51260 voxels (Figure 2 and Table 2). Again, taking the largest cluster as representative, neither sex ( $\mathrm{F}=0.50$, $\mathrm{df}=1, \mathrm{p}-0.49)$ nor ethnicity $(\mathrm{F}=0.64, \mathrm{df}=1, \mathrm{p}=0.43)$ were significant predictors of mean $\mathrm{FA}$, but age was so $(\mathrm{F}=17.60, \mathrm{df}=1, \mathrm{p}<0.001)$. Nevertheless, as above, the effect of genotype on $\mathrm{FA}$ in this cluster remained significant $(\mathrm{F}=5.80, \mathrm{df}=1, \mathrm{p}=0.02)$ after co-varying for age.

Figure 2. Effect of rs1344706 genotype on fractional anisotropy in schizophrenia. 
a

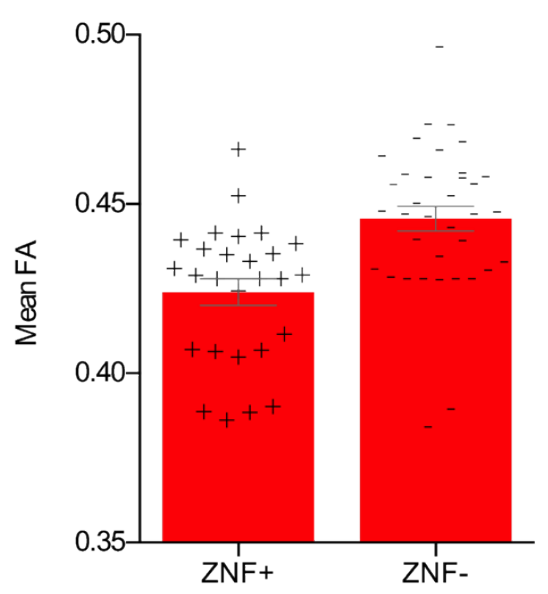

ZNF804A rs1344706 in SZ b

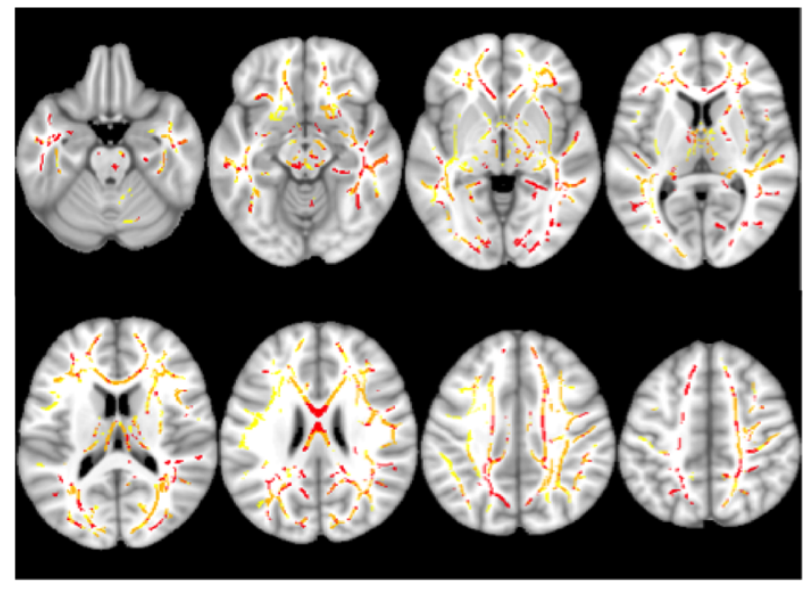

301

302

303

304

305

306

307

308

309

310

311

312 voxels. The clusters overlapped extensively (Figure 3 and Table 2) in the genu, body and

314 splenium of the corpus callosum, anterior corona radiata (including the optic radiation)

315 bilaterally, left external capsule and left superior longitudinal fasciculus. Neither ethnicity nor

316 sex were significant contributors to the variance in the mean FA of the largest cluster of the 
$317 \mathrm{SZ}<$ Control' contrast (ethnicity: $\mathrm{F}=0.73, \mathrm{df}=1, \mathrm{p}=0.39$; sex: $\mathrm{F}=2.79, \mathrm{df}=1, \mathrm{p}=0.10$ ) or the

318 ' $\mathrm{BD}<$ Control' contrast (ethnicity: $\mathrm{F}=1.17, \mathrm{df}=1, \mathrm{p}=0.28$; sex: $\mathrm{F}=1.46, \mathrm{df}=1, \mathrm{p}=0.23$ ) contrasts.

319 Age contributed significantly to FA variance in both clusters, as expected given that it is well

320 known to correlate with $\mathrm{FA}^{75}$, but the contribution of diagnosis remained highly significant as an

321 explanatory factor of FA variance after controlling for age (for the ' $\mathrm{SZ}<\mathrm{Control}$ ' cluster:

$322 \mathrm{~F}=26.99, \mathrm{df}=2, \mathrm{p}<0.001$; for the ' $\mathrm{BD}<\mathrm{Control}$ ' cluster: $\mathrm{F}=28.51, \mathrm{df}=2, \mathrm{p}<0.001)$. There was no

323 significant difference in FA between patient groups, nor regions where FA was significantly

324 decreased in controls compared to patients.

325

326 Figure 3. Main effect of diagnosis on fractional anisotropy.

a

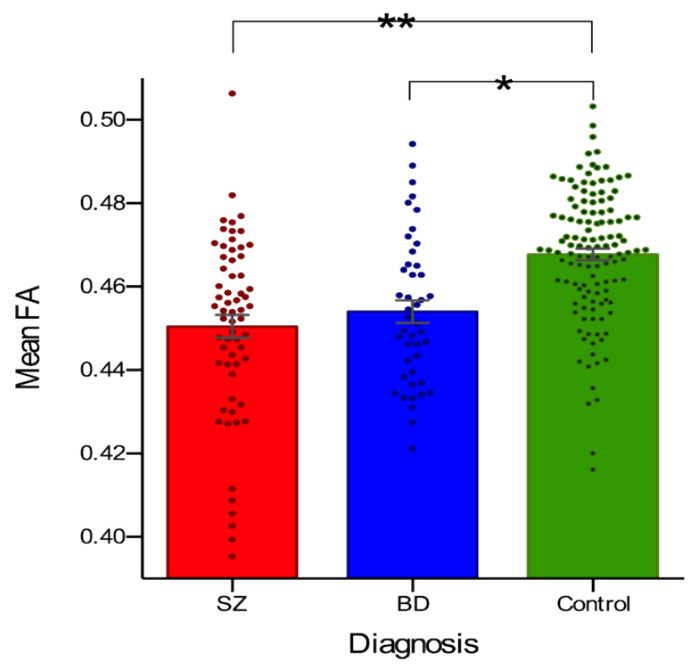

b

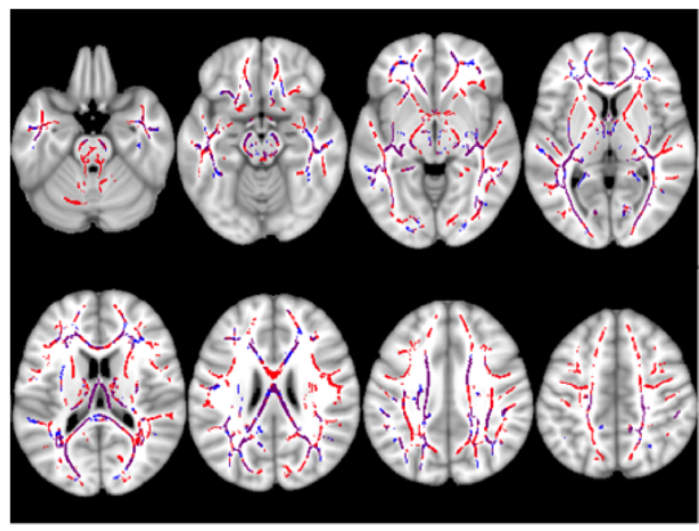

Figure 3 a. FA was significantly reduced in SZ compared to controls (marked **) and in BD compared to controls (marked *), $\mathbf{p}<0.05$, TFCE corrected. Post-hoc analyses in the largest significant clusters revealed a respective Cohen's $d$ of 0.91 and 1.19, both considered 'large'. The difference in FA between SZ and BD was not statistically significant. Individual data points show mean FA value for each participant within the largest cluster of the effect. b. Areas in which FA was significantly lower in SZ compared to controls are shown in red and areas where FA was significantly lower in BD compared to controls are shown in blue. Each effect 
334 encompassed one spatially extensive cluster. The overlapping areas, where both effects are significant are 335 shown in purple.

336

337 Genotype $x$ Diagnosis Interaction on FA

338 We found no WM areas where a genotype effect (in any direction) differed significantly between

339 diagnosis groups ( $<<0.05$, TFCE-corrected), testing every possible diagnosis-wise comparison.

340

341 


\section{Discussion}

343

344 We assessed the effect of ZNF804a rs1344706 genotype on FA, unprecedentedly, in a Caucasian

345 clinical sample, as well as in health, and whether this genotype effect was different between

346 diagnostic groups. For completeness, we also report FA differences between diagnostic groups.

347 We found three statistically significant effects ( $<<0.05$, TFCE-corrected): 1) a main effect of

348 genotype (irrespective of diagnosis), 2) an effect of genotype in the SZ patients group alone and

349 3) a main effect of diagnosis. We also detected no significant genotype by diagnosis interaction

350 effects. Our results provide further support for the involvement of the GWA-discovered

351 ZNF804A, in particular rs1344706 allele A, at least when in double-dose within a homozygous

352 genotype, in inducing susceptibility to psychosis by demonstrating its effect in reducing FA in

353 WM microstructure. We found unprecedented evidence in a predominantly Caucasian clinical

354 sample, of an association between rs1344706 risk allele A and reduced FA in a wide WM

355 network. Moreover, the opposite effect was found nowhere in the brain.

357 Our complementary post-hoc analyses using (for each individual) the mean FA across of the 358 most significant TFCE-corrected clusters of each effect provide a representative measure of size 359 magnitude and also allowed a better characterization of the significant main effect of genotype.

360 Irrespective of diagnosis, the FA high-risk group (ZNF+, i.e. A homozygotes) was about half of 361 a standard deviation lower (Cohen's d=0.48; Figure 1a) than that of the low-risk group (ZNF-,

362 i.e. C-carriers), which represents a 'medium'-sized effect ${ }^{76}$. In the same 'main effect of 363 genotype' cluster, both SZ and BD groups showed a 'large' effect of ZNF804A (SZ Cohen's d of 3640.83 and 0.89 respectively; Figure $1 \mathrm{~b}$ ), which are effects almost as large as the diagnosis effects 
365 on FA (see below). In contrast, the effect of genotype in controls had a 'small' effect (Cohen's

$366 \mathrm{~d}=0.2$ ). These effect sizes' comparison serve to demonstrate that the effect of genotype in

367 patients (both $\mathrm{SZ}$ and in $\mathrm{BD}$ ) rather than in controls, was driving this main effect of ZNF804A on

368 FA. A strong effect in patients is further supported, at least for SZ, by our findings of a large

369 overlapping network (Figure 2b) where an effect of genotype in SZ alone, is significant.

370 Nevertheless, this difference in genotype effect size between diagnostic groups was not reflected

371 in a significant TFCE-corrected genotype by diagnosis interaction in any area nor in the main

372 genotype effect cluster.

373

374 The present main effect of genotype has been recently replicated in a Caucasian sample ${ }^{38}$ who

375 found that higher A allele dosage predicted reduced FA in right parietal WM and left forceps

376 minor and, as in our study, the anterior body/genu of the corpus callosum. Importantly, both

377 theirs and our independent findings in the (inter-hemispheric) corpus callosum provide the

378 structural support to previous robust associations of this risk allele with reduced inter-

379 hemispheric functional connectivity between dorsolateral prefrontal cortices during working

380 memory, emotional face recognition and resting state ${ }^{13,77}$. Indeed, the observation that a SZ risk

381 allele could contribute to decreased prefrontal inter-hemispheric connectivity is consistent with

382 the disconnection hypothesis of SZ, which has been particularly verified between the two

383 hemispheres ${ }^{78}$. Moreover, the risk allele has also been associated with increased fronto-temporal

384 inter-hemispheric functional connectivity during working memory ${ }^{15,77}$, which was explained by

385 this particular coupling being abnormally persistent during working memory in SZ 18 .

386 Furthermore, our observation that the genotype effect we found was at its highest in the genu and

387 body of the corpus callosum is consistent with a previous report of inter-hemispheric connections 
388 being more heritable than intra-hemispheric or cortico-spinal ones ${ }^{79}$. This evidence suggests that

389 at least some of the genetic liability for psychosis may be acting on inter-hemispheric WM

390 microstructure.

391

392 The allele-wise direction of the present genotype effect is not only consistent with neuroimaging 393 and GWAs findings, but also links particularly well with gene-transcription findings. The risk

394 allele (A) has been associated with significantly higher gene expression than the $\mathrm{C}$ allele, in the

395 human dorso-lateral prefrontal cortex of healthy controls, and, at trend level, in SZ ${ }^{10}$. As alluded

396 to above, this region has been implicated in abnormalities in function and connectivity associated

397 with both SZ ${ }^{80}$ and this polymorphism, and is directly reliant on a major WM tract where we

398 report a large genotype effect: the superior longitudinal fasciculus. The same study ${ }^{10}$ also found,

399 bioinformatically, that the risk allele leads to the binding of two brain-expressed transcription

400 factors (Myt1L and POU3F1/Oct-6), involved in oligodendrocyte differentiation and transition

401 of pro-myelinating to myelinating Schwann cells. The $\mathrm{C}$ allele, however, results in binding of a

402 non-brain associated transcription factor. Taken with the present and current findings, this

403 suggests that the genomic region tagged by ZNF804A rs 1344706 may be influencing risk for SZ

404 and $\mathrm{BD}$, or affecting symptom dimensions putatively more dependent on FA in SZ patients (see

405 paragraph below), through differential provision of binding sites for transcription factors 406 involved in WM tract myelination.

407

408 The same effect of ZNF408A rs1344706 was statistically significant in the isolated SZ group 409 across widespread clusters which greatly overlapped with those where we found a main effect of 410 genotype (irrespective of diagnosis), reaching a large effect size (Cohen's d=1.01; Figure 3). No 
411 area showing a significant effect of ZNF804A was apparent for BD or controls in isolation. It is

412 thus plausible that there is some other etiological factor(s) acting in SZ patients that increase(s)

413 susceptibility to the effects of this risk variation on FA. Alternatively, rs1344706 is conferring

414 risk to specific symptom dimensions in SZ that may be more dependent on WM microstructure

415 in the reported areas. For example, healthy subjects have shown an association of the risk allele

416 and higher Schizotypal Personality Questionnaire (SPQ) score elsewhere ${ }^{81}$, with particular

417 deficits in disorganization domains, although this has been challenged by an allele-wise

418 incongruent finding ${ }^{82}$. The fact that these genotype effects were larger than the effect of the

419 same genotype on (the complex phenotype of) SZ or BD, typical of GWAs findings for mental

420 illness (i.e. a 'small' odds ratio of 1.12) ${ }^{6}$ is expected given the rationale that intermediate

421 phenotypes, or at least phenotypes less complex than behavior, are more closely related to 422 genetic variation.

424 The present significant genotype effect in SZ patients is consistent with the uncorrected trend 37

425 found in Chinese SZ patients, in the parietal lobes bilaterally, the right temporal lobe and the left

426 cingulate gyrus. However, the fact that the authors have not reported specific white fiber tracts

427 impedes localized comparison with the present study. The authors also report an opposite trend 428 in controls (to that in SZ) but it is of uncorrected statistical significance. In sum, our genotype429 wise findings on FA are consistent with two studies that have found a positive association 430 between rs1344706 and FA 48,83 and indirectly with nine studies that found an effect in 431 functional connectivity ${ }^{13-15,77,84-88}$, while three have failed to find an association ${ }^{34-36}$. 
433 Regarding main effects of diagnosis (controls vs. BD and SZ: Cohen's d=1.19 and 0.91,

434 respectively), our findings replicate previous solid research showing that both BD ${ }^{26}$ and SZ 25

435 are associated with reduced FA but with a larger difference in SZ ${ }^{30}$ : although the effect sizes

436 were similar, the FA reductions (TFCE-corrected) in SZ were almost 20 times more widespread

437 than that in $\mathrm{BD}$, compared to controls. Removing non-psychotic BD patients from the BD group

438 does not alter this estimate much (Cohen's d=1.09). Putting diagnosis and genotype-wise effects

439 in perspective, it should be noted that the (by far) largest significant clusters ( $p<0.05$, TFCE-

440 corrected) both of the main effect of genotype and of the genotype effect in SZ were up to two

441 thirds of that of the cluster size of the ' $\mathrm{SZ}<$ Controls' diagnosis effect (and more than 10 times

442 larger than the 'BD>Controls' cluster; Table 2).

443

444 As a potential limitation, not all diagnostic groups were matched for age and sex. There is 445 evidence of FA decreasing with age 75 and perhaps differing by sex (see below). Nevertheless, if 446 the effect of age would be confounding, BD patients would be expected to show decreased FA

447 (as their age was higher) compared to SZ and controls, but they in fact show higher FA 448 compared to SZ. Furthermore, age could not have confounded the finding of decreased FA in SZ 449 compared to controls, which were well-matched age-wise, since co-varying for age in this 450 situation would be expected to explain more of the error variance and thus further increase our 451 power to detect a true group effect rather than decreasing it. Finally, although the SZ group 452 contained a higher proportion of men than the control group, there is insufficient evidence to 453 suspect that this would have artefactually created the well-replicated finding of decreased FA in $454 \mathrm{SZ}^{25,89-91}$ and $\mathrm{BD}$ 26, 39, 92. Although higher FA for men was found in the superior cerebellar 455 peduncle, and for women in the corpus callosum ${ }^{93}$, there is also evidence ${ }^{94}$ that after controlling 
456 for intracranial volume, sex differences seem to be due to differences in head size. Above all,

457 these issues did not affect the main findings we report, i.e. the genotype effects, since the 458 genotype groups were balanced for these demographic factors. Moreover, post-hoc analyses with

459 the mean FA of the largest clusters of each significant contrast confirmed that the available 460 demographic variables did not confound the effects of genotype or diagnosis.

461

462 Another limitation of FA studies is that, technically, reduced FA, although commonly taken as a 463 proxy for reduced WM 'integrity' arising from deficient myelination, corresponds to heightened 464 water diffusion within a voxel which, in rigor, can be attributed not only to reduced myelination 465 but alternatively, or in conjunction, to several differences in WM microstructure: e.g. larger 466 axonal diameter, lower axonal density, higher membrane permeability or lower intra-voxel 467 orientational coherence of axonal fibers ${ }^{24}$. Thus, interpretation of FA should remain open. 468 Nevertheless, in demyelinating diseases such as multiple sclerosis, the attribution of reduced FA 469 to reduced myelination is immediate ${ }^{95}$, and evidence has also been pointing to deficient 470 myelination in $\mathrm{SZ}$ and $\mathrm{BD}{ }^{96,97}$, making the interpretation of FA reductions in $\mathrm{SZ}$ and $\mathrm{BD}$ as a 471 proxy for WM microstructural integrity reductions increasingly plausible.

\section{Conclusions}

475 In conclusion, the present findings support previous evidence that homozygosis for risk allele A 476 of SNP rs1344706 of ZNF804A confers risk for SZ and BD, and impaired functional 477 connectivity ${ }^{13-15}$, by offering a possible pathophysiological mechanism whereby this genetic 478 variant promotes reduced WM integrity in a widespread network. These results link particularly 
479 well with previous findings demonstrating that this risk variant, but not its counterpart, allows 480 binding affinity for transcription factors that might disrupt myelination ${ }^{10}$. 


\begin{tabular}{|c|c|c|c|c|c|c|c|c|}
\hline \multirow{2}{*}{$\begin{array}{l}\text { Participants' } \\
(\mathbf{n}=\mathbf{2 3 0})\end{array}$} & \multirow[t]{2}{*}{ Demographics } & \multicolumn{4}{|l|}{ Diagnosis } & \multicolumn{3}{|c|}{ ZNF804A rs1344706 Genotype } \\
\hline & & $\begin{array}{l}S Z \\
(n=63)\end{array}$ & $\begin{array}{l}\text { BD } \\
(n=43)\end{array}$ & $\begin{array}{l}\text { Controls } \\
(\mathrm{n}=124)\end{array}$ & $\begin{array}{l}\text { Statistic, df, p- } \\
\text { value }\end{array}$ & $\begin{array}{l}\text { ZNF+ } \\
(\mathrm{AA} ; \mathrm{n}=105)\end{array}$ & $\begin{array}{l}\text { ZNF- } \\
(A C \& C C ; n=125)\end{array}$ & $\begin{array}{l}\text { Statistic, df, p- } \\
\text { value }\end{array}$ \\
\hline \multicolumn{2}{|l|}{ Age (SD) } & $33.78(10.70)$ & $41.07(12.33)$ & $35.79(13.40)$ & $\begin{array}{l}\mathrm{F}=4.5, \quad \mathrm{df}=2, \\
\mathrm{p}=0.01^{\dagger}\end{array}$ & $36.94(13.66)$ & $35.62(11.87)$ & $\begin{array}{l}\mathrm{t}=-0.77, \quad \mathrm{df}=207.6 \\
\mathrm{p}=0.44\end{array}$ \\
\hline \multicolumn{2}{|c|}{ IQ z-scores (SD) } & $-0.75(2.89)$ & $-0.87(0.97)$ & $-0.68(3.51)$ & $\begin{array}{l}\mathrm{F}=0.70, \quad \mathrm{df}=2, \\
\mathrm{p}=0.50\end{array}$ & $-0.85(3.35)$ & $-0.33(2.61)$ & $\begin{array}{l}\mathrm{t}=1.22, \quad \mathrm{df}=197, \\
\mathrm{p}=0.23\end{array}$ \\
\hline \multicolumn{2}{|c|}{$\begin{array}{l}\text { CPZ- equivalent antipsychotics } \\
\text { dose (SD) }\end{array}$} & $696.94(613.02)$ & $341.60(434.56)$ & $\mathrm{n} / \mathrm{a}$ & $\begin{array}{l}\mathrm{t}=3.28, \quad \mathrm{df}=104, \\
\mathrm{p}<0.001^{\dagger}\end{array}$ & $641.93(634.06)$ & $484.45(516.18)$ & $\begin{array}{l}\mathrm{t}=-1.41, \quad \mathrm{df}=104, \\
\mathrm{p}=0.16\end{array}$ \\
\hline \multicolumn{2}{|c|}{ Years of Education (SD) } & $13.74(2.61)$ & $14.81(3.10)$ & $14.90(2.79)$ & $\begin{array}{l}\mathrm{F}=2.51, \quad \mathrm{df}=2, \\
\mathrm{p}=0.08\end{array}$ & $14.36(2.73)$ & $14.74(2.95)$ & $\begin{array}{l}\mathrm{t}=0.85, \quad \mathrm{df}=162, \\
\mathrm{p}=0.40\end{array}$ \\
\hline \multicolumn{2}{|l|}{$\operatorname{Sex}(M / F)$} & $50 / 13$ & $18 / 25$ & $67 / 57$ & $\begin{array}{l}\chi^{2}=17.24, \quad \mathrm{df}=2, \\
\mathrm{p}=<0.001\end{array}$ & $60 / 45$ & $75 / 50$ & $\begin{array}{l}\chi^{2}=0.19, \quad \mathrm{df}=1, \\
\mathrm{p}=0.66\end{array}$ \\
\hline \multirow[t]{7}{*}{ Ethnicity (n) } & Caucasian & 46 & 40 & 104 & \multirow{7}{*}{$\begin{array}{l}\chi^{2}=13.90, d f=12, \\
p=0.31\end{array}$} & 79 & 111 & \multirow{7}{*}{$\begin{array}{l}\chi^{2}=20.86, \quad \mathrm{df}=6, \\
\mathrm{p}=<0.001<0.001\end{array}$} \\
\hline & $\begin{array}{l}\text { Black } \\
\text { Caribbean } \\
\end{array}$ & 6 & 1 & 4 & & 11 & 0 & \\
\hline & Black African & 5 & 2 & 6 & & 10 & 3 & \\
\hline & Central Asian & 3 & 0 & 4 & & 2 & 5 & \\
\hline & $\begin{array}{l}\text { Mixed African- } \\
\text { Caucasian }\end{array}$ & 2 & 0 & 1 & & 1 & 2 & \\
\hline & Eastern Asian & 0 & 0 & 3 & & 1 & 2 & \\
\hline & Other & 1 & 0 & 2 & & 1 & 2 & \\
\hline \multirow{3}{*}{$\begin{array}{l}\text { Handedness } \\
\text { (n) }\end{array}$} & Right & 62 & 38 & 112 & \multirow{3}{*}{$\begin{array}{l}\chi^{2}=5.79, \quad \mathrm{df}=4, \\
\mathrm{p}=0.22\end{array}$} & 93 & 119 & \multirow{3}{*}{$\begin{array}{l}\chi^{2}=3.88, \quad \mathrm{df}=2, \\
\mathrm{p}=0.14\end{array}$} \\
\hline & Left & 0 & 3 & 5 & & 6 & 2 & \\
\hline & Mixed & 1 & 2 & 7 & & 6 & 4 & \\
\hline \multirow{3}{*}{$\begin{array}{l}\text { Genotype } \\
\text { counts }(\%)\end{array}$} & $\overline{\mathbf{A A}}$ & $27(42.9)$ & $19(44.2)$ & $59(47.6)$ & \multirow[t]{3}{*}{$\mathrm{n} / \mathrm{a}$} & \multirow{3}{*}{\multicolumn{3}{|c|}{$\mathrm{n} / \mathrm{a}$}} \\
\hline & $\overline{\mathbf{A C}}$ & $28(44.4)$ & $16(37.2)$ & $51(41.1)$ & & & & \\
\hline & $\overline{C C}$ & $8(12.7)$ & $8(18.6)$ & $14(11.3)$ & & & & \\
\hline
\end{tabular}

Footnote: $n / a=$ not applicable; ${ }^{\dagger}$ statistically significant at $p<0.05 . Z N F+:$ High risk (AA genotypes); ZNF-: Low risk (AC\&CC genotypes); BD: bipolar disorder; SZ: schizophrenia; SD: standard deviation; $d f$ : degrees of freedom. ${ }^{S}$ Scores of full scale IQ from the Wechsler Abbreviated Scale of Intelligence (WASI) ${ }^{67}$, the Wechsler Adult Intelligence Scale-Revised (WAIS-R) ${ }^{68}$ or the National Adult Reading Test (NART) ${ }^{69}$ were standardised to Z-scores to permit between-group IQ comparison. (The type of test 


\section{PeerJ}

used was balanced between diagnostic or genotype groups.) 


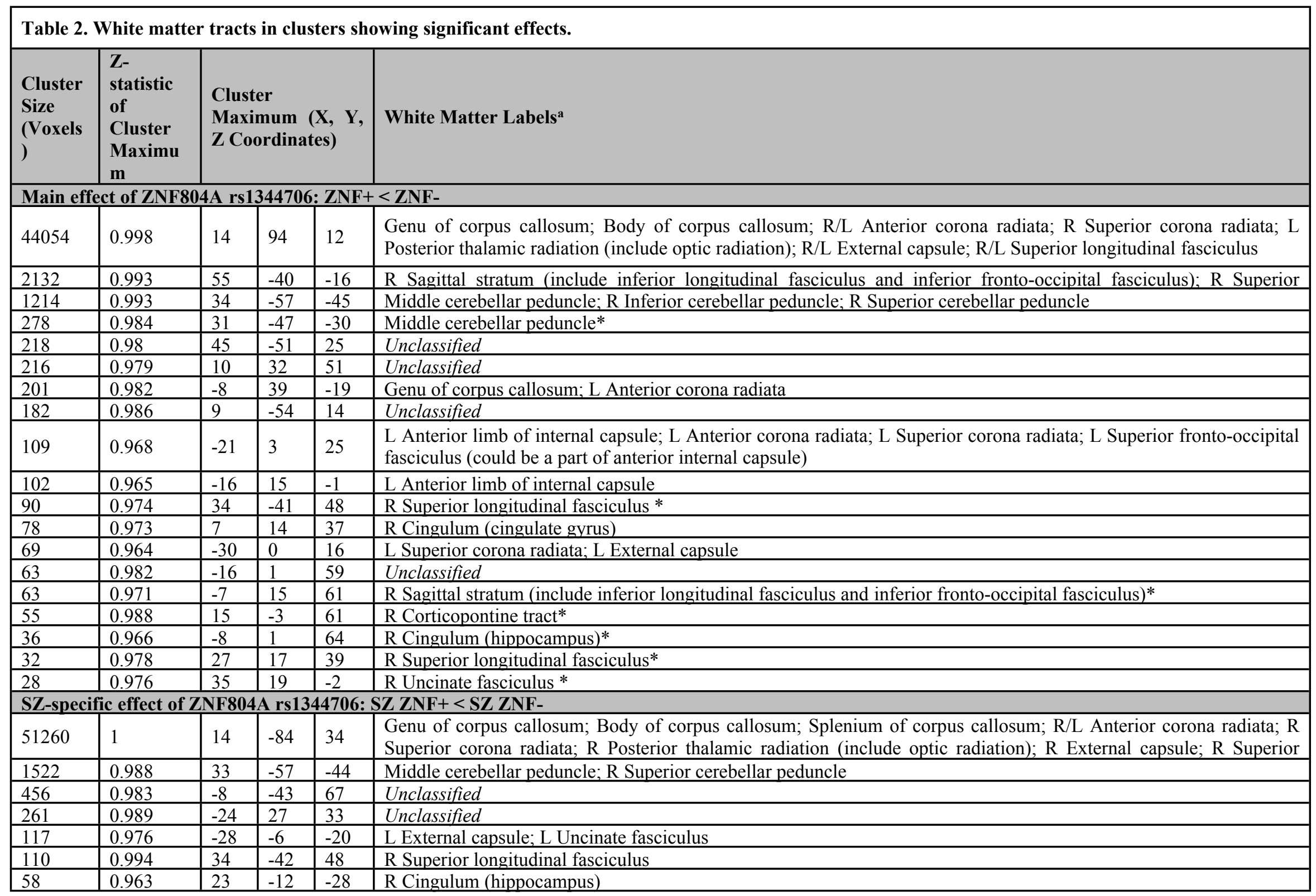




\begin{tabular}{|l|l|l|l|l|l|}
\hline 53 & 0.963 & -2 & -36 & -45 & L Pontine crossing tract; Corticospinal tract; L Medial lemniscus \\
\hline 49 & 0.975 & 3 & -59 & -12 & R Uncinate fasciculus* \\
\hline 36 & 0.964 & -39 & 4 & 44 & Unclassified \\
\hline 34 & 0.979 & 16 & -46 & -24 & R Inferior cerebellar peduncle \\
\hline 29 & 0.967 & 11 & 27 & 20 & R Cingulum (cingulate gyrus) \\
\hline 29 & 0.983 & -7 & -51 & -48 & Unclassified \\
\hline 22 & 0.961 & 41 & 34 & 6 & R Sagittal stratum (include inferior longitudinal fasciculus and inferior fronto-occipital fasciculus)* \\
\hline 21 & 0.976 & -31 & 2 & 29 & L Superior longitudinal fasciculus \\
\hline 21 & 0.963 & 29 & -4 & -31 & Unclassified \\
\hline Main effect of BD diagnosis: BD $<$ Controls \\
\hline \\
3882 & 0.998 & -17 & 25 & 23 & $\begin{array}{l}\text { Genu of corpus callosum; Body of corpus callosum; Splenium of corpus callosum; L Cerebral peduncle; R/L } \\
\text { Retrolenticular part of internal capsule; R/L Anterior corona radiata; L Superior corona radiata; R/L Posterior } \\
\text { thalamic radiation (include optic radiation); R Sagittal stratum (include inferior longitudinal fasciculus and inferior } \\
\text { fronto-occipital fasciculus); L External capsule; L Superior longitudinal fasciculus }\end{array}$ \\
\hline
\end{tabular}

\section{Footnote:}

ZNF+: High risk (AA genotypes); ZNF-: Low risk (AC\&CC genotypes); BD: bipolar disorder; SZ: schizophrenia; FA: fractional anisotropy (a putative proxy for white matter microstructural integrity).

${ }^{a}$ Only tracts with clusters at $>1 \%$ probability, after threshold-free cluster enhancement (TFCE) correction, are included. White matter labels are provided in accordance with JHU ICBM-DTI-81 White Matter Atlas ${ }^{72}$ using AtlasQuery in FSL unless marked with "*”, in which case they were based on MRI Atlas of Human White Matter (1st Edition by Mori et al., 2005 - see methods) due to retrieval from AtlasQuery as 'Unclassified'. When this was not possible, regions remained 482 
484

485

486

487

488

489

490

491

492

493

494

495

496

497

498

499

500

501

502

503

504

505

506

507

508

509

510

511

512

513

514

515

516

517

518

519

520

521

522

523

524

525

526

527

528

\section{References}

1. Bhugra D. The Global Prevalence of Schizophrenia. PLoS Medicine. 2005;2(5):e151.

2. Merikangas K AS, Angst J, Greenberg P, Hirschfeld R, Petukhova M, Kessler R. Lifetime and 12-month prevalence of bipolar spectrum disorder in the national comorbidity survey replication. Archives of General Psychiatry. 2007;64(5):543-552.

3. Gurung R, Prata DP. What is the impact of genome-wide supported risk variants for schizophrenia and bipolar disorder on brain structure and function? A systematic review. Psychol Med. 2015:1-20.

4. Walters JT, Corvin A, Owen MJ, Williams H, Dragovic M, Quinn EM, Judge R, Smith DJ, Norton N, Giegling I, Hartmann AM, Moller HJ, Muglia P, Moskvina V, Dwyer S, O'Donoghue T, Morar B, Cooper M, Chandler D, Jablensky A, Gill M, Kaladjieva L, Morris DW, O'Donovan MC, Rujescu D, Donohoe G. Psychosis susceptibility gene ZNF804A and cognitive performance in schizophrenia. Arch Gen Psychiatry. 2010;67(7):692-700.

5. Bernstein HG, Steiner J, Dobrowolny H, Bogerts B. ZNF804A protein is widely expressed in human brain neurons: possible implications on normal brain structure and pathomorphologic changes in schizophrenia. Schizophr Bull. 2014;40(3):499-500.

6. Donohoe G, Morris DW, Corvin A. The psychosis susceptibility gene ZNF804A: associations, functions, and phenotypes. Schizophr Bull. 2010;36(5):904-909.

7. Girgenti MJ, LoTurco JJ, Maher BJ. ZNF804a regulates expression of the schizophreniaassociated genes PRSS16, COMT, PDE4B, and DRD2. PLoS One. 2012;7(2):e32404.

8. Chung HJ, Lee JY, Deocaris CC, Min H, Kim SH, Kim MH. Mouse Homologue of the Schizophrenia Susceptibility Gene ZNF804A as a Target of Hoxc8. J Biomed Biotechnol. 2010;2010:231708.

9. Hill MJ, Jeffries AR, Dobson RJ, Price J, Bray NJ. Knockdown of the psychosis susceptibility gene ZNF804A alters expression of genes involved in cell adhesion. Hum Mol Genet. 2012;21(5):1018-1024.

10. Riley B, Thiselton D, Maher BS, Bigdeli T, Wormley B, McMichael GO, Fanous AH, Vladimirov V, O'Neill FA, Walsh D, Kendler KS. Replication of association between schizophrenia and ZNF804A in the Irish Case-Control Study of Schizophrenia sample. Mol Psychiatry. 2010;15(1):29-37.

11. Hill MJ, Bray NJ. Allelic differences in nuclear protein binding at a genome-wide significant risk variant for schizophrenia in ZNF804A. Mol Psychiatry. 2011;16(8):787789.

12. Tao R, Cousijn H, Jaffe AE, Burnet PW, Edwards F, Eastwood SL, Shin JH, Lane TA, Walker MA, Maher BJ, Weinberger DR, Harrison PJ, Hyde TM, Kleinman JE. Expression of ZNF804A in human brain and alterations in schizophrenia, bipolar disorder, and major depressive disorder: a novel transcript fetally regulated by the psychosis risk variant rs1344706. JAMA Psychiatry. 2014;71(10):1112-1120.

13. Esslinger C, Kirsch P, Haddad L, Mier D, Sauer C, Erk S, Schnell K, Arnold C, Witt SH, Rietschel M, Cichon S, Walter H, Meyer-Lindenberg A. Cognitive state and connectivity effects of the genome-wide significant psychosis variant in ZNF804A. Neuroimage. 2011;54(3):2514-2523.

14. Walter H, Schnell K, Erk S, Arnold C, Kirsch P, Esslinger C, Mier D, Schmitgen MM, Rietschel M, Witt SH, Nothen MM, Cichon S, Meyer-Lindenberg A. Effects of a 
genome-wide supported psychosis risk variant on neural activation during a theory-ofmind task. Mol Psychiatry. 2011;16(4):462-470.

15. Paulus FM, Krach S, Bedenbender J, Pyka M, Sommer J, Krug A, Knake S, Nöthen MM, Witt SH, Rietschel M, Kircher T, Jansen A. Partial support for ZNF804A genotypedependent alterations in prefrontal connectivity. Human Brain Mapping. 2013;34(2):304313.

16. Ohtani T, Bouix S, Hosokawa T, Saito Y, Eckbo R, Ballinger T, Rausch A, Melonakos E, Kubicki M. Abnormalities in white matter connections between orbitofrontal cortex and anterior cingulate cortex and their associations with negative symptoms in schizophrenia: a DTI study. Schizophr Res. 2014;157(1-3):190-197.

17. Wang X, Xia M, Lai Y, Dai Z, Cao Q, Cheng Z, Han X, Yang L, Yuan Y, Zhang Y, Li $\mathrm{K}$, Ma H, Shi C, Hong N, Szeszko P, Yu X, He Y. Disrupted resting-state functional connectivity in minimally treated chronic schizophrenia. Schizophr Res. 2014;156(23):150-156.

18. Meyer-Lindenberg AS, Olsen RK, Kohn PD, Brown T, Egan MF, Weinberger DR, Berman KF. Regionally specific disturbance of dorsolateral prefrontal-hippocampal functional connectivity in schizophrenia. Archives of General Psychiatry. 2005;62(4):379-386.

19. Makris N, Seidman LJ, Ahern T, Kennedy DN, Caviness VS, Tsuang MT, Goldstein JM. White matter volume abnormalities and associations with symptomatology in schizophrenia. Psychiatry Res. 2010;183(1):21-29.

20. McDonald C, Bullmore E, Sham P, Chitnis X, Suckling J, MacCabe J, Walshe M, Murray RM. Regional volume deviations of brain structure in schizophrenia and psychotic bipolar disorder: computational morphometry study. $\mathrm{Br} J$ Psychiatry. 2005; 186:369-377.

21. McDonald C, Bullmore ET, Sham PC, Chitnis X, Wickham H, Bramon E, Murray RM. Association of genetic risks for schizophrenia and bipolar disorder with specific and generic brain structural endophenotypes. Arch Gen Psychiatry. 2004;61(10):974-984.

22. McIntosh AM, Job DE, Moorhead TW, Harrison LK, Lawrie SM, Johnstone EC. White matter density in patients with schizophrenia, bipolar disorder and their unaffected relatives. Biol Psychiatry. 2005;58(3):254-257.

23. Kuswanto CN, Teh I, Lee TS, Sim K. Diffusion tensor imaging findings of white matter changes in first episode schizophrenia: a systematic review. Clin Psychopharmacol Neurosci. 2012;10(1):13-24.

24. Jones DK, Knosche TR, Turner R. White matter integrity, fiber count, and other fallacies: the do's and don'ts of diffusion MRI. Neuroimage. 2013;73:239-254.

25. Ellison-Wright I, Bullmore E. Meta-analysis of diffusion tensor imaging studies in schizophrenia. Schizophr Res. 2009;108(1-3):3-10.

26. Vederine FE, Wessa M, Leboyer M, Houenou J. A meta-analysis of whole-brain diffusion tensor imaging studies in bipolar disorder. Prog Neuropsychopharmacol Biol Psychiatry. 2011;35(8):1820-1826.

27. Carletti F, Woolley JB, Bhattacharyya S, Perez-Iglesias R, Fusar Poli P, Valmaggia L, Broome MR, Bramon E, Johns L, Giampietro V, Williams SC, Barker GJ, McGuire PK. Alterations in white matter evident before the onset of psychosis. Schizophr Bull. 2012;38(6):1170-1179. 
574

575

576

577

578

579

580

581

582

583

584

585

586

587

588

589

590

591

592

593

594

595

596

597

598

599

600

601

602

603

604

605

606

607

608

609

610

611

612

613

614

615

616

617

618

619

28. Kochunov P, Jahanshad N, Marcus D, Winkler A, Sprooten E, Nichols TE, Wright SN, Hong LE, Patel B, Behrens T, Jbabdi S, Andersson J, Lenglet C, Yacoub E, Moeller S, Auerbach E, Ugurbil K, Sotiropoulos SN, Brouwer RM, Landman B, Lemaitre H, den Braber A, Zwiers MP, Ritchie S, van Hulzen K, Almasy L, Curran J, deZubicaray GI, Duggirala R, Fox P, Martin NG, McMahon KL, Mitchell B, Olvera RL, Peterson C, Starr J, Sussmann J, Wardlaw J, Wright M, Boomsma DI, Kahn R, de Geus EJ, Williamson DE, Hariri A, van 't Ent D, Bastin ME, McIntosh A, Deary IJ, Hulshoff Pol HE, Blangero J, Thompson PM, Glahn DC, Van Essen DC. Heritability of fractional anisotropy in human white matter: a comparison of Human Connectome Project and ENIGMA-DTI data. Neuroimage. 2015;111:300-311.

29. Prasad KM, Upton CH, Schirda CS, Nimgaonkar VL, Keshavan MS. White matter diffusivity and microarchitecture among schizophrenia subjects and first-degree relatives. Schizophr Res. 2015;161(1):70-75.

30. Skudlarski P, Schretlen DJ, Thaker GK, Stevens MC, Keshavan MS, Sweeney JA, Tamminga CA, Clementz BA, O'Neil K, Pearlson GD. Diffusion tensor imaging white matter endophenotypes in patients with schizophrenia or psychotic bipolar disorder and their relatives. Am J Psychiatry. 2013;170(8):886-898.

31. Sprooten E, Brumbaugh MS, Knowles EE, McKay DR, Lewis J, Barrett J, Landau S, Cyr L, Kochunov P, Winkler AM, Pearlson GD, Glahn DC. Reduced white matter integrity in sibling pairs discordant for bipolar disorder. Am J Psychiatry. 2013;170(11):1317-1325.

32. Phillips OR, Nuechterlein KH, Asarnow RF, Clark KA, Cabeen R, Yang Y, Woods RP, Toga AW, Narr KL. Mapping corticocortical structural integrity in schizophrenia and effects of genetic liability. Biol Psychiatry. 2011;70(7):680-689.

33. Emsell L, Chaddock C, Forde N, Van Hecke W, Barker GJ, Leemans A, Sunaert S, Walshe M, Bramon E, Cannon D, Murray R, McDonald C. White matter microstructural abnormalities in families multiply affected with bipolar I disorder: a diffusion tensor tractography study. Psychol Med. 2013:1-12.

34. Fernandes CP, Westlye LT, Giddaluru S, Christoforou A, Kauppi K, Adolfsson R, Nilsson LG, Nyberg L, Lundervold AJ, Reinvang I, Steen VM, Le Hellard S, Espeseth T. Lack of association of the rs1344706 ZNF804A variant with cognitive functions and DTI indices of white matter microstructure in two independent healthy populations. Psychiatry Res. 2014;222(1-2):60-66.

35. Sprooten E, McIntosh AM, Lawrie SM, Hall J, Sussmann JE, Dahmen N, Konrad A, Bastin ME, Winterer G. An investigation of a genomewide supported psychosis variant in ZNF804A and white matter integrity in the human brain. Magn Reson Imaging. 2012;30(10):1373-1380.

36. Wei Q, Kang Z, Diao F, Guidon A, Wu X, Zheng L, Li L, Guo X, Hu M, Zhang J, Liu C, Zhao J. No association of ZNF804A rs1344706 with white matter integrity in schizophrenia: a tract-based spatial statistics study. Neurosci Lett. 2013;532:64-69.

37. Kuswanto CN, Woon P-S, Zheng XB, Qiu A, Sitoh Y-Y, Chan YH, Liu J, Williams H, Ong WY, Sim K. Genome-wide supported psychosis risk variant in ZNF804A gene and impact on cortico-limbic WM integrity in schizophrenia. American Journal of Medical Genetics Part B: Neuropsychiatric Genetics. 2012;159B(3):255-262.

38. Ikuta T, Peters BD, Guha S, John M, Karlsgodt KH, Lencz T, Szeszko PR, Malhotra AK. A schizophrenia risk gene, ZNF804A, is associated with brain white matter microstructure. Schizophrenia Research.155(1):15-20. 
620 39. Nortje G, Stein DJ, Radua J, Mataix-Cols D, Horn N. Systematic review and voxel-based

621

622

623

624

625

626

627

628

629

630

631

632

633

634

635

636

637

638

639

640

641

642

643

644

645

646

647

648

649

650

651

652

653

654

655

656

657

658

659

660

661

662

663

664

665 meta-analysis of diffusion tensor imaging studies in bipolar disorder. J Affect Disord. 2013;150(2):192-200.

40. Schwab SG, Kusumawardhani AA, Dai N, Qin W, Wildenauer MD, Agiananda F, Amir N, Antoni R, Arsianti T, Asmarahadi A, Diatri H, Djatmiko P, Irmansyah I, Khalimah S, Kusumadewi I, Kusumaningrum P, Lukman PR, Mustar L, Nasrun MW, Naswati S, Prasetiyawan P, Semen GM, Siste K, Tobing H, Widiasih N, Wiguna T, Wulandari WD, Benyamin B, Wildenauer DB. Association of rs1344706 in the ZNF804A gene with schizophrenia in a case/control sample from Indonesia. Schizophr Res. 2013;147(1):4652.

41. Allin MP, Kontis D, Walshe M, Wyatt J, Barker GJ, Kanaan RA, McGuire P, Rifkin L, Murray RM, Nosarti C. White matter and cognition in adults who were born preterm. PLoS One. 2011;6(10):e24525.

42. Chaddock CA, Barker GJ, Marshall N, Schulze K, Hall MH, Fern A, Walshe M, Bramon E, Chitnis XA, Murray R, McDonald C. White matter microstructural impairments and genetic liability to familial bipolar I disorder. Br J Psychiatry. 2009;194(6):527-534.

43. Chaddock CA. Psychosis as a diconnection syndrome: an MRI study of familial bipolar I disorder and schizophrenia: Division of Psychological Medicine and Psychiatry, Institute of Psychiatry, King's College London; 2009.

44. Kane F. Cerebral function and connectivity in twins with bipolar disorder [Ph.D.]: Institute of Psychiatry, University of London, King's College London; 2008.

45. Kyriakopoulos M, Perez-Iglesias R, Woolley JB, Kanaan RA, Vyas NS, Barker GJ, Frangou S, McGuire PK. Effect of age at onset of schizophrenia on white matter abnormalities. Br J Psychiatry. 2009;195(4):346-353.

46. Picchioni MM, Toulopoulou T, Landau S, Davies N, Ribchester T, Murray RM. Neurological abnormalities in schizophrenic twins. Biol Psychiatry. 2006;59(4):341-348.

47. Shergill SS, Kanaan RA, Chitnis XA, O'Daly O, Jones DK, Frangou S, Williams SC, Howard RJ, Barker GJ, Murray RM, McGuire P. A diffusion tensor imaging study of fasciculi in schizophrenia. Am J Psychiatry. 2007;164(3):467-473.

48. Kuswanto CN, Woon PS, Zheng XB, Qiu A, Sitoh YY, Chan YH, Liu J, Williams H, Ong WY, Sim K. Genome-wide supported psychosis risk variant in ZNF804A gene and impact on cortico-limbic WM integrity in schizophrenia. Am J Med Genet B Neuropsychiatr Genet. 2012;159B(3):255-262.

49. Schultz CC, Nenadic I, Riley B, Vladimirov VI, Wagner G, Koch K, Schachtzabel C, Muhleisen TW, Basmanav B, Nothen MM, Deufel T, Kiehntopf M, Rietschel M, Reichenbach JR, Cichon S, Schlosser RG, Sauer H. ZNF804A and cortical structure in schizophrenia: in vivo and postmortem studies. Schizophr Bull. 2014;40(3):532-541.

50. Donohoe G, Rose E, Frodl T, Morris D, Spoletini I, Adriano F, Bernardini S, Caltagirone C, Bossu P, Gill M, Corvin AP, Spalletta G. ZNF804A risk allele is associated with relatively intact gray matter volume in patients with schizophrenia. Neuroimage. 2011;54(3):2132-2137.

51. Saville CW, Lancaster TM, Davies TJ, Toumaian M, Pappa E, Fish S, Feige B, Bender S, Mantripragada KK, Linden DE, Klein C. Elevated P3b latency variability in carriers of ZNF804A risk allele for psychosis. Neuroimage. 2015;116:207-213.

52. American.Psychiatric.Association, DSM-IV. APATFo. Diagnostic and statistical manual of mental disorders: DSM-IV: Amer Psychiatric Pub Inc; 1994. 
666

667

668

669

670

671

672

673

674

675

676

677

678

679

680

681

682

683

684

685

686

687

688

689

690

691

692

693

694

695

696

697

698

699

700

701

702

703

704

705

706

707

708

709

710

53. Prata DP, Mechelli A, Fu CH, Picchioni M, Toulopoulou T, Bramon E, Walshe M, Murray RM, Collier DA, McGuire P. Epistasis between the DAT 3' UTR VNTR and the COMT Val158Met SNP on cortical function in healthy subjects and patients with schizophrenia. Proc Natl Acad Sci U S A. 2009;106(32):13600-13605.

54. Kendler KS. The genetics of schizophrenia: chromosomal deletions, attentional disturbances, and spectrum boundaries. Am J Psychiatry. 2003;160(9):1549-1553.

55. Freeman B, Smith N, Curtis C, Huckett L, Mill J, Craig IW. DNA from buccal swabs recruited by mail: evaluation of storage effects on long-term stability and suitability for multiplex polymerase chain reaction genotyping. Behav Genet. 2003;33(1):67-72.

56. Applied.Biosystems. TaqMan SNP Genotyping Assays Protocol. Foster City, California 94404, USA 2010.

57. Court MH. Court's online calculator 2005-2008.

58. Jones DK, Williams SC, Gasston D, Horsfield MA, Simmons A, Howard R. Isotropic resolution diffusion tensor imaging with whole brain acquisition in a clinically acceptable time. Hum Brain Mapp. 2002;15(4):216-230.

59. Smith SM. Fast robust automated brain extraction. Hum Brain Mapp. 2002;17(3):143155.

60. Behrens TE, Woolrich MW, Jenkinson M, Johansen-Berg H, Nunes RG, Clare S, Matthews PM, Brady JM, Smith SM. Characterization and propagation of uncertainty in diffusion-weighted MR imaging. Magn Reson Med. 2003;50(5):1077-1088.

61. Smith SM, Jenkinson M, Johansen-Berg H, Rueckert D, Nichols TE, Mackay CE, Watkins KE, Ciccarelli O, Cader MZ, Matthews PM, Behrens TE. Tract-based spatial statistics: voxelwise analysis of multi-subject diffusion data. Neuroimage. 2006;31(4):1487-1505.

62. Smith SM, Jenkinson M, Woolrich MW, Beckmann CF, Behrens TE, Johansen-Berg H, Bannister PR, De Luca M, Drobnjak I, Flitney DE, Niazy RK, Saunders J, Vickers J, Zhang Y, De Stefano N, Brady JM, Matthews PM. Advances in functional and structural MR image analysis and implementation as FSL. Neuroimage. 2004;23 Suppl 1:S208-219.

63. Andersson JLR, Jenkinson M, Smith S. Non-linear registration, aka Spatial normalisation. http://www.fmrib.ox.ac.uk/analysis/techrep 2007.

64. Andersson JLR, Jenkinson M, Smith S. Non-linear optimisation. http://www.fmrib.ox.ac.uk/analysis/techrep 2007.

65. Rueckert D, Sonoda LI, Hayes C, Hill DL, Leach MO, Hawkes DJ. Nonrigid registration using free-form deformations: application to breast MR images. IEEE Trans Med Imaging. 1999;18(8):712-721.

66. IBM SPSS Statistic for Windows, Version 21.0 [computer program]. Version. Armonk, NY: IBM Corp; 2012.

67. Wechsler D. Wechsler abbreviated scale of intelligence: Psychological Corporation; 1999.

68. Wechsler D. WAIS-R manual: Wechsler adult intelligence scale-revised: Psychological Corporation; 1981.

69. Nelson $\mathrm{H}$, Willison $\mathrm{J}$. The revised national adult reading test-test manual. Windsor: NFER-Nelson. 1991.

70. Anderson M, Robinson J. Permutation tests for linear models. Aust. N.Z. J. Stat. 2001;43(1):75-88. 
711 71. Smith SM, Nichols TE. Threshold-free cluster enhancement: addressing problems of

712

713

714

715

716

717

718

719

720

721

722

723

724

725

726

727

728

729

730

731

732

733

734

735

736

737

738

739

740

741

742

743

744

745

746

747

748

749

750

751

752

753

754

755 smoothing, threshold dependence and localisation in cluster inference. Neuroimage. 2009;44(1):83-98.

72. Mori S, Oishi K, Jiang H, Jiang L, Li X, Akhter K, Hua K, Faria AV, Mahmood A, Woods R, Toga AW, Pike GB, Neto PR, Evans A, Zhang J, Huang H, Miller MI, van Zijl $\mathrm{P}$, Mazziotta J. Stereotaxic white matter atlas based on diffusion tensor imaging in an ICBM template. Neuroimage. 2008;40(2):570-582.

73. Mori S, Wakana S, van Zijl PCM, Nagae-Poetscher LM. MRI Atlas of Human White Matter: Elsevier Science; 2005.

74. Sherry ST, Ward MH, Kholodov M, Baker J, Phan L, Smigielski EM, Sirotkin K. dbSNP: the NCBI database of genetic variation. Nucleic Acids Res. 2001;29(1):308-311.

75. Sullivan EV, Pfefferbaum A. Diffusion tensor imaging and aging. Neurosci Biobehav Rev. 2006;30(6):749-761.

76. Cohen J. Statistical power analysis for the behavioral sciences. Hillsdale, N.J.: L. Erlbaum Associates; 1988.

77. Esslinger C, Walter H, Kirsch P, Erk S, Schnell K, Arnold C, Haddad L, Mier D, Opitz von Boberfeld C, Raab K, Witt SH, Rietschel M, Cichon S, Meyer-Lindenberg A. Neural mechanisms of a genome-wide supported psychosis variant. Science. 2009;324(5927):605.

78. Stephan KE, Baldeweg T, Friston KJ. Synaptic plasticity and dysconnection in schizophrenia. Biol Psychiatry. 2006;59(10):929-939.

79. Shen K-K, Rose S, Fripp J, McMahon KL, de Zubicaray GI, Martin NG, Thompson PM, Wright MJ, Salvado O. Investigating brain connectivity heritability in a twin study using diffusion imaging data. NeuroImage. 2014;100:628-641.

80. Makris N, Kennedy DN, McInerney S, Sorensen AG, Wang R, Caviness VS, Jr., Pandya DN. Segmentation of subcomponents within the superior longitudinal fascicle in humans: a quantitative, in vivo, DT-MRI study. Cereb Cortex. 2005;15(6):854-869.

81. Yasuda Y, Hashimoto R, Ohi K, Fukumoto M, Umeda-Yano S, Yamamori H, Okochi T, Iwase M, Kazui H, Iwata N, Takeda M. Impact on schizotypal personality trait of a genome-wide supported psychosis variant of the ZNF804A gene. Neurosci Lett. 2011;495(3):216-220.

82. Stefanis NC, Hatzimanolis A, Avramopoulos D, Smyrnis N, Evdokimidis I, Stefanis CN, Weinberger DR, Straub RE. Variation in psychosis gene ZNF804A is associated with a refined schizotypy phenotype but not neurocognitive performance in a large young male population. Schizophr Bull. 2013;39(6):1252-1260.

83. Ikuta T, Peters BD, Guha S, John M, Karlsgodt KH, Lencz T, Szeszko PR, Malhotra AK. A schizophrenia risk gene, ZNF804A, is associated with brain white matter microstructure. Schizophr Res. 2014;155(1-3):15-20.

84. Cousijn H, Tunbridge EM, Rolinski M, Wallis G, Colclough GL, Woolrich MW, Nobre AC, Harrison PJ. Modulation of hippocampal theta and hippocampal-prefrontal cortex function by a schizophrenia risk gene. Hum Brain Mapp. 2015;36(6):2387-2395.

85. Mohnke S, Erk S, Schnell K, Schutz C, Romanczuk-Seiferth N, Grimm O, Haddad L, Pohland L, Garbusow M, Schmitgen MM, Kirsch P, Esslinger C, Rietschel M, Witt SH, Nothen MM, Cichon S, Mattheisen M, Muhleisen T, Jensen J, Schott BH, Maier W, Heinz A, Meyer-Lindenberg A, Walter H. Further evidence for the impact of a genome- 
756

757

758

759

760

761

762

763

764

765

766

767

768

769

770

771

772

773

774

775

776

777

778

779

780

781

782

783

784

785

786

787

788

789

790

791

792

793

794

795

796 wide-supported psychosis risk variant in ZNF804A on the Theory of Mind Network. Neuropsychopharmacology. 2014;39(5):1196-1205.

86. Rasetti R, Sambataro F, Chen Q, Callicott JH, Mattay VS, Weinberger DR. Altered cortical network dynamics: a potential intermediate phenotype for schizophrenia and association with ZNF804A. Arch Gen Psychiatry. 2011;68(12):1207-1217.

87. Lencz T, Szeszko PR, DeRosse P, Burdick KE, Bromet EJ, Bilder RM, Malhotra AK. A schizophrenia risk gene, ZNF804A, influences neuroanatomical and neurocognitive phenotypes. Neuropsychopharmacology. 2010;35(11):2284-2291.

88. Linden DE, Lancaster TM, Wolf C, Baird A, Jackson MC, Johnston SJ, Donev R, Thome J. ZNF804A genotype modulates neural activity during working memory for faces. Neuropsychobiology. 2013;67(2):84-92.

89. Reading SA, Oishi K, Redgrave GW, McEntee J, Shanahan M, Yoritomo N, Younes L, Mori S, Miller MI, van Zijl P, Margolis RL, Ross CA. Diffuse abnormality of low to moderately organized white matter in schizophrenia. Brain Connect. 2011;1(6):511-519.

90. Scheel M, Prokscha T, Bayerl M, Gallinat J, Montag C. Myelination deficits in schizophrenia: evidence from diffusion tensor imaging. Brain Struct Funct. 2013;218(1):151-156.

91. Schneiderman JS, Hazlett EA, Chu KW, Zhang J, Goodman CR, Newmark RE, Torosjan Y, Canfield EL, Entis J, Mitropoulou V, Tang CY, Friedman J, Buchsbaum MS. Brodmann area analysis of white matter anisotropy and age in schizophrenia. Schizophr Res. 2011;130(1-3):57-67.

92. Lagopoulos J, Hermens DF, Hatton SN, Tobias-Webb J, Griffiths K, Naismith SL, Scott EM, Hickie IB. Microstructural white matter changes in the corpus callosum of young people with Bipolar Disorder: a diffusion tensor imaging study. PLoS One. 2013;8(3):e59108.

93. Kanaan RA, Chaddock C, Allin M, Picchioni MM, Daly E, Shergill SS, McGuire PK. Gender influence on white matter microstructure: a tract-based spatial statistics analysis. PLoS One. 2014;9(3):e91109.

94. Takao H, Hayashi N, Ohtomo K. Sex dimorphism in the white matter: fractional anisotropy and brain size. J Magn Reson Imaging. 2014;39(4):917-923.

95. Werring DJ, Clark CA, Barker GJ, Thompson AJ, Miller DH. Diffusion tensor imaging of lesions and normal-appearing white matter in multiple sclerosis. Neurology. 1999;52(8):1626-1632.

96. Du F, Cooper AJ, Thida T, Shinn AK, Cohen BM, Ongur D. Myelin and axon abnormalities in schizophrenia measured with magnetic resonance imaging techniques. Biol Psychiatry. 2013;74(6):451-457.

97. Regenold WT, Phatak P, Marano CM, Gearhart L, Viens CH, Hisley KC. Myelin staining of deep white matter in the dorsolateral prefrontal cortex in schizophrenia, bipolar disorder, and unipolar major depression. Psychiatry Res. 2007;151(3):179-188. 